\title{
Large-scale patterns of plant diversity and conservation priorities in South East Asia
}

\author{
S.T. Marsh ${ }^{1}$, N.A. Brummitt ${ }^{1}$, R.P.J. de Kok ${ }^{1}$, T.M.A. Utteridge ${ }^{1}$
}

\section{Key words}

conservation

floristic relationships

generic diversity

South East Asia

\begin{abstract}
In the absence of a complete floristic inventory, conservation priorities within South East Asia must often be based on incomplete knowledge or a rough approximation of diversity such as habitat cover. To help overcome this, a database containing distribution data for all 3523 known flowering plant genera across 53 geo-political regions covering all of Indo-China, Malesia and the Pacific has been compiled from regional floras and herbarium specimens at the Royal Botanic Gardens, Kew. Our database is currently $85 \%$ complete and has been used in this preliminary analysis to show the broad patterns of plant diversity and floristic relationships in the South East Asian region. The aim of this paper is to demonstrate the floristic richness, at genus level across the region, the relationships between the different areas and to highlight the areas within the region that are of most pressing conservation concern.
\end{abstract}

Published on 30 October 2009

\section{INTRODUCTION}

South East Asia has long been recognised as a centre of plant biodiversity (Mittermeier et al. 1999). Being situated in the tropics, with areas of high rainfall and a year round hot humid climate, South East Asia boasts some of the largest numbers of vascular plants species in the world (Mittermeier et al. 1999). In this analysis, we consider the regions in South East Asia and the Pacific as defined by the Taxonomic Databases Working Group (TDWG) Level 2 regions (Brummitt 2001): 41 (Myanmar, Thailand, Laos, Vietnam, Cambodia, Andaman Islands, Nicobar Islands, South China Sea Islands); 42 (Peninsular Malaysia, Philippines, Sumatra, Java, Lesser Sunda Islands, Borneo, Maluku, Sulawesi, Cocos (Keeling) Islands, Christmas Island); 43 (New Guinea, Bismarck Archipelago, Solomon Islands); 60-63 (Pacific Islands and island groups including Vanuatu, New Caledonia, Fiji, Tonga, Samoa, Hawaii and the smaller Pacific island nations). This large area contains many habitat types and has a very interesting geological history. It is reported to contain a vascular flora of 20 000-25 000 species in Indo-China, 42000 species in Malesia and $5000+$ species in the Pacific (Frodin 2001). The South East Asian and Pacific regions overlap with 7 of the hotspots defined by Myers et al. (2000) and Conservation International (2008) (Indo-Burma, Philippines, Sundaland, Wallaceae, East Melanesian Islands, New Caledonia, Polynesia-Micronesia). These are areas of the world that contain high concentrations of endemic vascular plant species and are undergoing immense habitat loss (Myers et al. 2000). The only area within the region missing this hotspot status is the island of New Guinea; the main reason for this is that New Guinea is undergoing less habitat loss than other areas. In a later treatment Mittermeier et al. (2003) argued the need for proactive conservation by protecting vast areas of wilderness where $70 \%$ or more of the ecosystem remains intact and there is a human density of less than or equal to 5 people per $\mathrm{km}^{2}$. New Guinea is listed as one of the 5 wildernesses with the most endemic plant and vertebrate species targeted for conservation.

\footnotetext{
Royal Botanic Garden, Kew, Richmond, Surrey, TW9 3AE, United Kingdom.
}

The floristic region of Malesia in particular has been the subject of many investigations into floristic biodiversity and historical biogeography (for overviews see Johns 1995, Ridder-Numan 1996, Whitmore 1982). Scientific interest in the Malay Archipelago dates back to Wallace and his travels in the region in the mid-19th century (Schuster 1974). Wallace noted marked differences between islands in the archipelago in the occurrence of several animal species and suggested a demarcation line dividing the archipelago into two halves. This line, now known as Wallace's Line, has been shown to be a consequence of past historical biogeographic events, like ice ages and/or plate tectonics, including the collision of Laurasia and Gondwanaland in the tertiary (Whitmore 1982). The collision of the two great continents, made up of several ocean and land plates, has created a unique geological history. The region Wallacea (covering the Lesser Sunda Islands to the east of Bali and the islands between the east of Borneo and west of the province of Papua on the island of New Guinea) is made up of land fragments of Gondwanaland and various island arcs, which were never part of either the Sunda (mainland Asia and mainly Sumatra, Java and Borneo) or Sahul (Australia and mainly New Guinea and surrounding islands) shelves during the last series of ice ages (see Ridder-Numan 1996). Furthermore, speciation in the whole South East Asia region has been aided by fluctuating sea levels, by the periodical isolation of mountainous areas at times of high sea level and the presence of land bridges connecting the islands and mainland at times of low levels. As a consequence, together with its tropical climate, areas of South East Asia have evolved to contain highly endemic biotas. Geological history however, is not the only factor that makes South East Asia such a floristically diverse region, it also has high geodiversity (diversity of abiotic parameters), most notably topography and variation in altitude. Global centres of vascular plant diversity are correlated with highly geodiverse areas in the tropics and subtropics (Mutke \& Barthlott 2005), Van Welzen et al. (2005) also noted an apparent correlation between geological activities in a region and the number of endemic species. For example, Mt Kinabalu in North Borneo (Beaman 2005) has c. 5000 species in an area of $1200 \mathrm{~km}^{2}$. South East Asia contains four of the 12 areas of the world that represent the global maxima of vascular plant species richness (Mutke \& Barthlott 2005) and all these maxima are closely linked to mountainous areas.

(c) 2009 Nationaal Herbarium Nederland

You are free to share - to copy, distribute and transmit the work, under the following conditions:

Attribution: $\quad$ You must attribute the work in the manner specified by the author or licensor (but not in any way that suggests that they endorse you or your use of the work). 
Mutke \& Barthlott (2005) state that "knowledge on spatial distribution of biodiversity is crucial for its further exploration, use, and conservation" (p. 521). Several large-scale research programmes have demonstrated this need and the usefulness of them in politics and conservation programmes such as Conservation International (www.biodiversityhotspots.org 2008) Hotspots and the WWF Global 200 (Olson \& Dinerstein 1998, Olson et al. 2001). However, continental and global scale biodiversity maps are still scarce (Mutke \& Barthlott 2005) and we hope our analysis helps to partially rectify this.

For conservation purposes large-scale regional distribution maps of plant diversity are likely to be useful in areas that face large-scale destruction. Deforestation is particularly severe in South East Asia, it is predicted to lose $75 \%$ of its natural forests by 2100 and up to $42 \%$ of its biodiversity (Achard et al. 2002, Sodhi et al. 2004). The habitat type that is most under threat is lowland rain forest, which used to be the most common vegetation type in the recent past (Davis 1995). The major threats to lowland forest are logging, agriculture and in particular the planting of Oil Palm (Sodhi et al. 2004). The Human footprint and the Last of the Wild project (Sanderson et al. 2002) aimed to map human impacts on the earth using four types of data: population density, land transformation, accessibility and electrical power infrastructure. The resulting map reveals in vivid colour the scale of human impact around the globe, however it does not take into account deforestation. But with the combined use of biodiversity maps and human influence maps it may be possible to highlight the 'right' areas for more conservation efforts, or to step up efforts in areas that are shown to have high biodiversity and are severely under threat from human activities.

\section{METHODS}

We extracted a total of 3523 flowering plant genera native to South East Asia and the Pacific from an existing database of all vascular plant genera and their global distributions scored according to the Level 2 regions of the Taxonomic Databases Working Group (TDWG) (Brummitt 2001) held at RBG Kew (Brummitt 2005). We developed a new MS Access relational database to store distributions of all these native flowering plant genera across 53 TDWG Level 3 regions of South East Asia and the Pacific. The distribution data was compiled for each genus from a combination of specimen and literature records to create a database of slightly more than 25000 distribution records. We then queried this database for numbers of genera and endemic genera for each region (Fig. 1, 4, Table 1). We used the standard power-law species area relationship $S=c A^{z}$ to compare diversities between regions of different size, rearranging the formula and correcting numbers of genera with the formula $c=S / A^{z}$ (Brummitt \& Nic Lughadha 2003) and standardising this to a common size of $100000 \mathrm{~km}^{2}$; areas for each region were calculated with ArcGIS 9.1. We then used a separate linear regression model to standardise numbers of genera per equal area for collecting effort, these data having been compiled from Van Steenis-Kruseman (1974) and Campbell \& Hammond (1989) and interpolated for missing areas, as if each area had 100 specimens collected per 100 $\mathrm{km}^{2}$ ('well-collected' sensu Van Steenis-Kruseman; see also Johns 1995) (Table 1). This allowed us to compare estimated diversity between different regions, differences in size and collecting effort thus being corrected for. We then used the Human Footprint dataset (Sanderson et al. 2002) to add relative human impacts across the region, calculating a mean Human Footprint value for each region and we have highlighted areas of particular importance for conservation where high levels of plant diversity coincide with a high Human Footprint (Fig. 3). We also analysed floristic relatedness between different regions at genus level within South East Asia and the Pacific with UPGMA clustering using a relative Sørensen's coefficient in the software package PC-Ord 4.0 (McCune \& Mefford 1999); results from this are given in Fig. 5 .

\section{RESULTS}

Fig. 1 shows the number of endemic genera (above) and number of genera (below) for each region within South East Asia (see also Table 1 and Fig. 4). Although a preliminary analysis from an almost-complete dataset, we do not expect the pattern of generic richness to change, but the total numbers of genera

Table 1 Numbers of genera, endemic genera and numbers of genera standardised by area for each TDWG Level 3 region (Brummitt 2001) of South East Asia and the Pacific. Numbers of genera were standardised using a power-law regression for the species-area relationship $S=c A^{z}$ (Brummitt \& Nic Lughadha 2003) as if each region were $100000 \mathrm{~km}^{2}$.

\begin{tabular}{|c|c|c|c|c|c|c|c|}
\hline $\begin{array}{l}\text { TDWG } \\
\text { Level } 2 \\
\text { code }\end{array}$ & $\begin{array}{l}\text { TDWG } \\
\text { Level } 3 \\
\text { code }\end{array}$ & $\begin{array}{l}\text { TDWG } \\
\text { Level } 3 \\
\text { region }\end{array}$ & $\begin{array}{l}\text { number of } \\
\text { genera }\end{array}$ & $\begin{array}{l}\text { number of } \\
\text { endemic } \\
\text { genera }\end{array}$ & $\begin{array}{l}\text { number of genera } \\
\text { standardized } \\
\text { by area }\end{array}$ & $\begin{array}{l}\text { number of genera } \\
\text { standardized } \\
\text { by collecting } \\
\text { intensity }\end{array}$ & $\begin{array}{l}\text { mean Human } \\
\text { Footprint } \\
\text { value }\end{array}$ \\
\hline 41 & AND & Andaman Is. & 453 & & 943 & 360 & 34.90 \\
\hline 41 & CBD & Cambodia & 686 & & 598 & 922 & 21.95 \\
\hline 41 & LAO & Laos & 767 & 4 & 622 & 1028 & 20.74 \\
\hline 41 & MYA & Myanmar & 1304 & 10 & 812 & 1987 & 19.91 \\
\hline 41 & SCS & South China Sea & 39 & & 291 & & 0.62 \\
\hline 41 & THA & Thailand & 1605 & 17 & 1097 & 1959 & 24.60 \\
\hline 41 & VIE & Vietnam & 1401 & 21 & 1061 & 1642 & 28.12 \\
\hline 42 & BOR & Borneo & 1396 & 31 & 841 & 1704 & 20.27 \\
\hline 42 & XMS & Christmas I. & 172 & & 980 & & 33.66 \\
\hline 42 & $\mathrm{CKI}$ & Cocos (Keeling) Is. & 62 & & 438 & & 3.48 \\
\hline 42 & JAW & Jawa & 1403 & 3 & 1307 & 1206 & 41.05 \\
\hline 42 & LSI & Lesser Sunda Is. & 812 & 1 & 802 & 964 & 31.53 \\
\hline 42 & MOL & Maluku & 898 & 3 & 1026 & 1009 & 23.88 \\
\hline 42 & $\mathrm{PHI}$ & Philippines & 1406 & 20 & 1062 & 1467 & 33.79 \\
\hline 42 & SUL & Sulawesi & 1000 & 5 & 850 & 1285 & 30.68 \\
\hline 42 & SUM & Sumatra & 1300 & 7 & 877 & 1696 & 28.99 \\
\hline 43 & BIS & Bismarck Archipelago & 509 & 1 & 612 & 687 & 26.00 \\
\hline 43 & NWG & New Guinea & 1424 & 48 & 844 & 1624 & 16.72 \\
\hline 43 & SOL & Solomon Is. & 665 & 3 & 861 & 556 & 29.53 \\
\hline
\end{tabular}




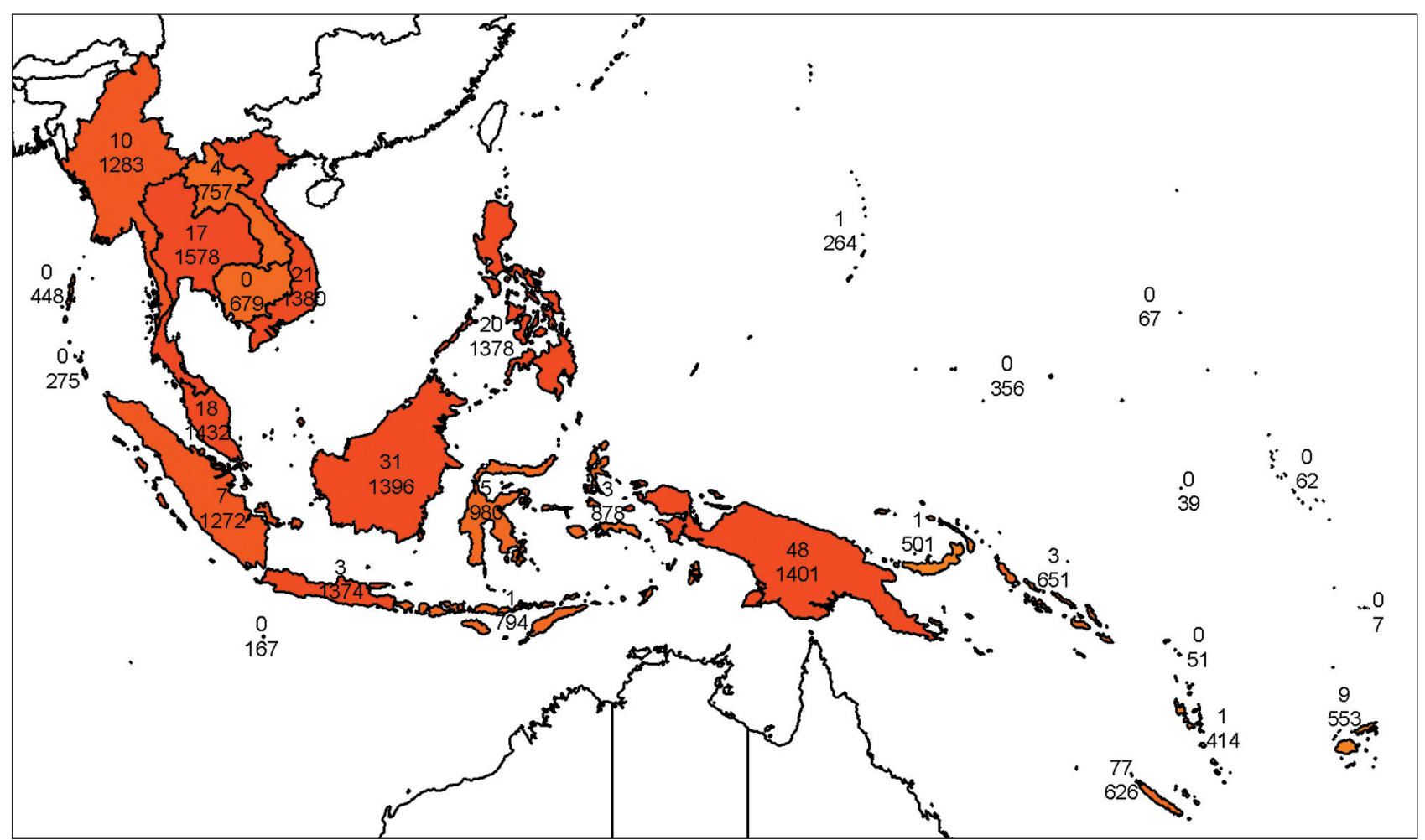

Fig. 1 Map of South East Asia showing number of endemic genera (above) and number of genera (below) for each area, overall generic diversity is shaded from light yellow (poor) to deep red (rich). Although a preliminary analysis, we do not expect the pattern of generic richness to change, but the total numbers of genera and endemic genera will increase slightly.

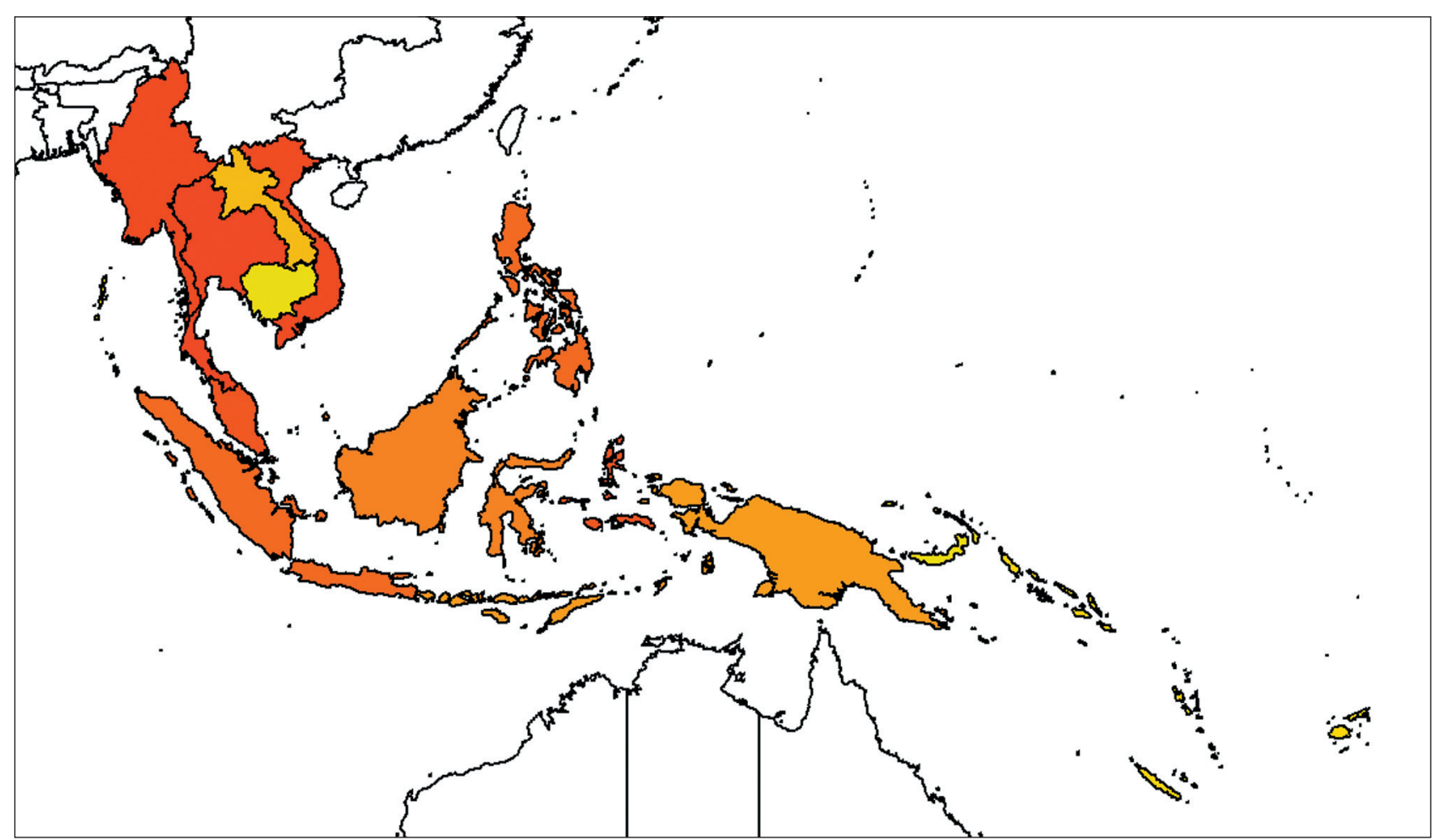

Fig. 2 Map of South East Asia showing generic density corrected for collecting intensity (data from Van Steenis-Kruseman 1974, Campbell \& Hammond 1989) and size, as if each area had 100 specimens per $100 \mathrm{~km}^{2}$ ('well-collected') and was $100000 \mathrm{~km}^{2}$. Generic diversity is shaded from light yellow (poor) to deep red (rich), large, well-collected areas are less diverse.

and endemic genera will increase slightly for most regions. These patterns of diversity are similar at generic level to those shown for Malesia at species level by Van Welzen et al. (2005), showing that numbers of genera are proportional to numbers of species for each region of South East Asia. However, with the added areas of Indo-China we can see that, at generic level, comparable levels of high diversity are also found in Indo-China. Indeed, when standardised for the size of each region (see Table 1), both Thailand and Vietnam appear in the five most diverse regions for genera ( $3 \mathrm{rd}$ and 5 th, respectively).

A map of generic density rescaled for collecting intensity as well as size is shown in Fig. 2, as if each area had 100 specimens 


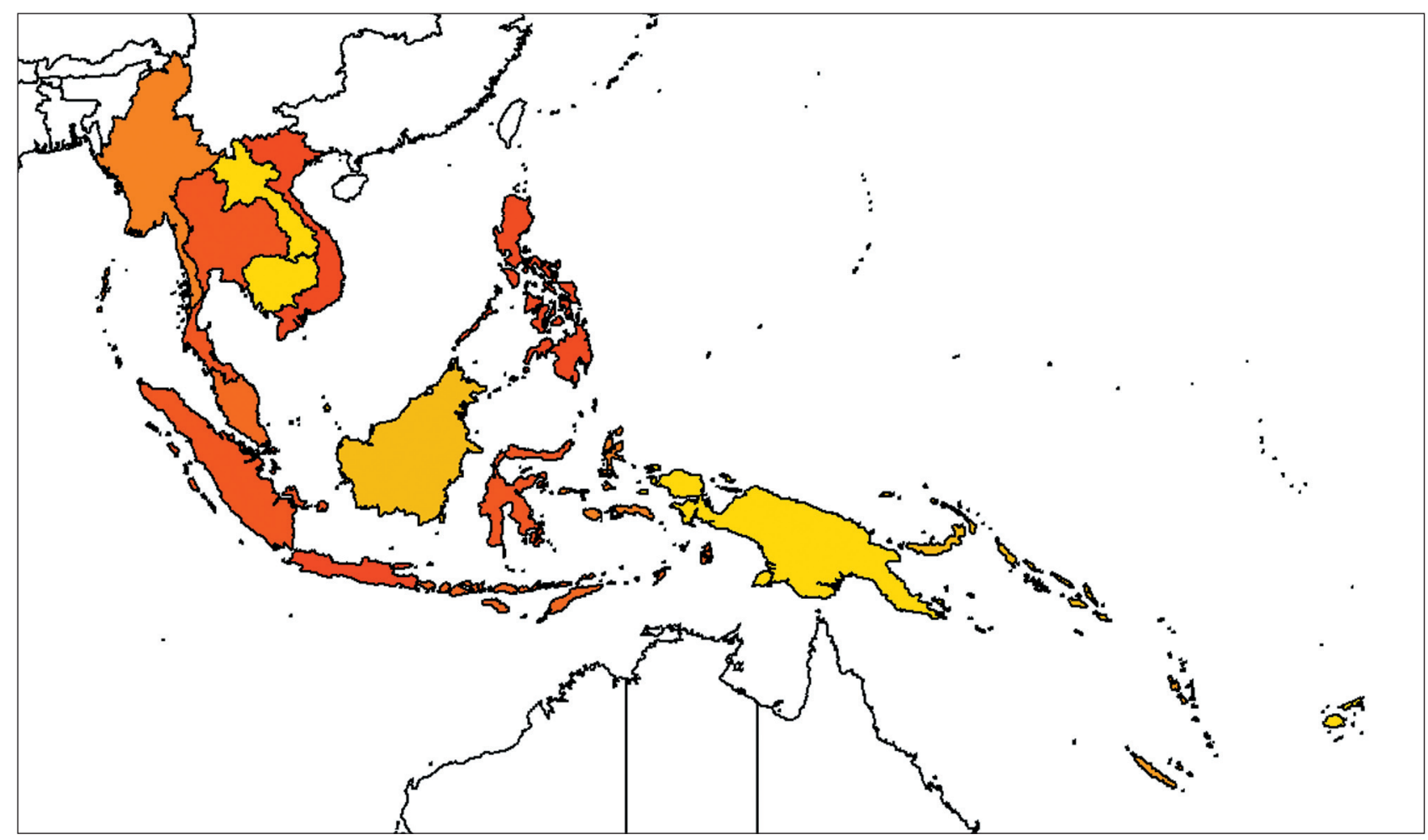

Fig. 3 Map of areas in South East Asia with both high generic richness and under significant threat from human activities. Richness data is corrected for area $\left(100000 \mathrm{~km}^{2}\right)$ and collection density $\left(100 / 100 \mathrm{~km}^{2}\right)$, Human Footprint data from Sanderson et al. (2002). The shading shows low-threat areas with relatively low biodiversity (pale yellow) through to high-threat areas with relatively high biodiversity (deep red).

per $100 \mathrm{~km}^{2}$ (so could be called 'well-collected' in the use of this term by Van Steenis-Kruseman) and was $100000 \mathrm{~km}^{2}$. Large, relatively well-collected areas now appear less diverse, in particular Borneo and New Guinea; however, regions of relatively poorly-collected regions of Indo-China such as Burma [Myanmar], Thailand and Vietnam now appear to be more diverse. As a measure of conservation priority, mean values for Human Footprint were calculated in ArcView GIS, and a map of areas in South East Asia with both high generic richness and under significant threat from human activities is shown in Fig. 3. As can be seen in Fig. 3, large, relatively intact Wilderness areas (Mittermeier et al. 2003) such as New Guinea appear to be much less of a conservation priority than do other regions with high human impact such as Thailand and Vietnam, both of which now appear as of greater conservation concern than does much of the Malesian region.

A dendrogram of floristic relationships within the South East Asia region is given in Fig. 5. Indo-China is closely aligned with the core Malesian region, and New Guinea (NWG) is closely aligned to Malesia and not to the Bismarck Archipelago (BIS) and the Solomon Islands (SOL). The island groups of the South West Pacific, including the Bismarck Archipelago and the Solomon Islands now often regarded as part of the South East Asia region (Johns 1995), are instead grouped together with the rest of the Pacific, forming a distinct cluster of Pacific island groups. This is partly due to the large size of, and hence large number of genera found in, New Guinea: although most genera found in the Bismarck Archipelago and the Solomon Islands might also be found in both New Guinea and other island groups of the South West Pacific, there are many more genera in New Guinea found in Malesia but not shared with the South West Pacific regions. Whether or not one chooses to regard this as evidence that the Solomon Islands are 'closer' floristically to the South West Pacific than to the Malesian region depends on one's definition of floristic 'closeness'.

\section{DISCUSSION}

In this paper, the floristic relatedness of TDWG regions within South East Asia and the Pacific is analysed at genus level, using UPGMA clustering analysis under a relative Sørensen's coefficient. One of the interesting findings of our study is that the data suggest, that at genus level, the eastern boundary of Malesia lies between the island of New Guinea and the Bismarck Archipelago (Fig. 5). The eastern boundary for Malesia has been variously interpreted in the past (for a more detailed account see Johns 1995) with Johns himself placing a demarcation knot at the eastern boundary of Papuasia (New Guinea and island groups east up to and including the Solomon Islands). Van Welzen et al. (2005) also place the eastern boundary of Malesia in the West Pacific in their study analysing species diversity from the Flora Malesiana. Our analysis disputes this at a generic level and agrees with Van Steenis's (1950) original boundary.

We also found that the entire region of South East Asia is almost equally rich in its floristic biodiversity (excluding the Pacific islands) at genus level (Fig. 1, 2). The islands of Borneo and New Guinea showed the highest numbers of endemic genera. This is not surprising as Van Welzen et al. (2005) had similar, and more pronounced, results with an analysis based on species level data. However, in both analyses, this correlation has not been statistically tested and further analysis is needed. Moreover, Thailand and Vietnam also showed high levels of endemism and general generic richness, showing that high biodiversity is not limited to the moist tropical forests of Malesia or to islands. Of course, it is difficult to really predict if these areas that are now poorly known will continue to yield novelties at the same rate as better-collected areas have done, but an analysis of numbers of new species published over a 5-year period across the IndoPacific region might hint at whether or not this will be the case. Indo-China, although less mountainous than areas of Malesia, 

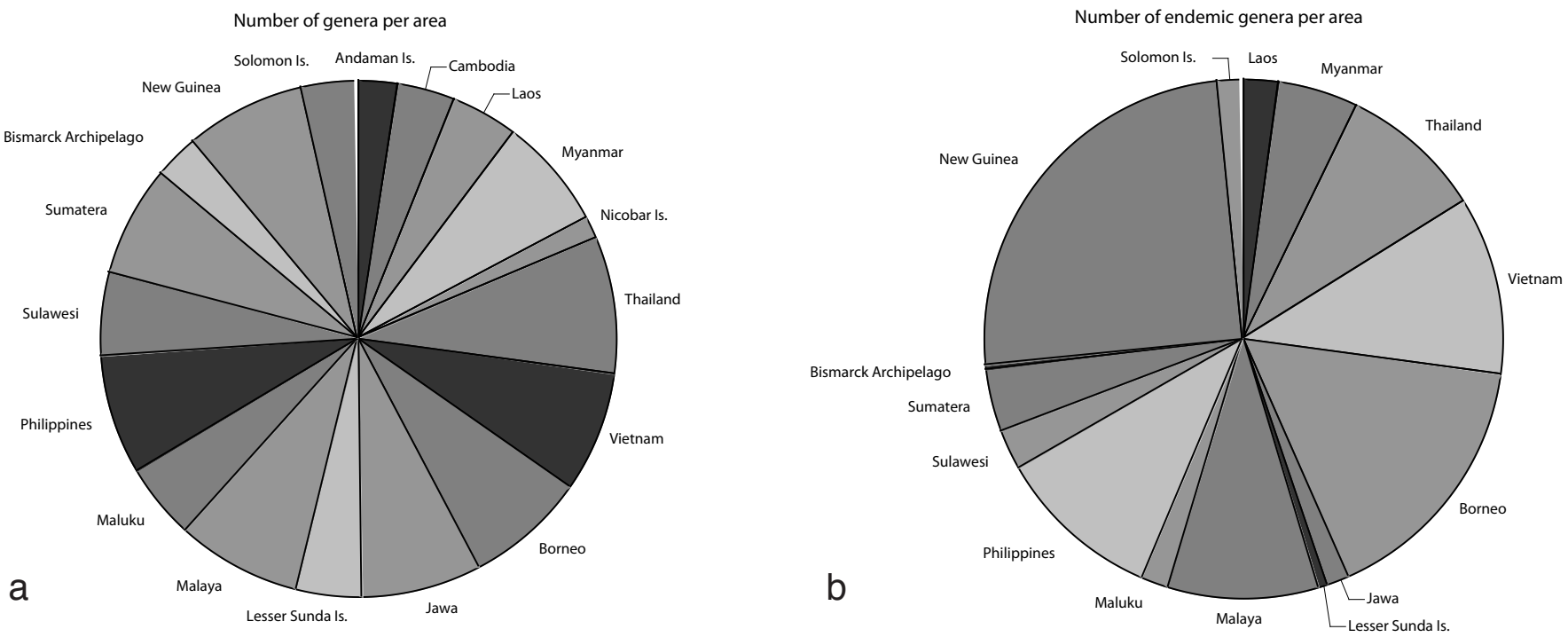

Fig. 4 a. Pie chart showing numbers of genera per TDWG region in South East Asia; b. pie chart showing numbers of endemic genera per TDWG region in South East Asia.

is geodiverse with habitats including mixed wet evergreen, dry evergreen, deciduous, and montane forest.

In the Conservation International hotspots analysis (2008) the region of South East Asia and the Pacific is treated as 7 different, but almost continuous, hotspots. The only area missing the hotspot status is the island of New Guinea. The Conservation International criteria for an area being a hotspot are a high level of species endemism (> 1500 vascular plants) and $70 \%$ loss of natural habitat. In our analysis using the data combined with that of the Human Footprint, we reach similar conclusions. The main reason for this is that the dataset with the floristic data has much less variation in it (each area is more or less as floristically rich as any other area in South East Asia) and therefore, the much greater variation in the Human Footprint dataset, will cause it to dominate any combined analysis. As New Guinea is (thankfully) not yet as threatened by human activity as other areas in the region, this area is perhaps of less conservation concern at the moment than the equally rich but more densely populated areas such as Java and the Philippines. However, New Guinea is included in Mittermeier et al. (2003) wilderness areas. Due to its largely intact $(>70 \%)$ habitat and low human density, New Guinea is a target of proactive conservation. Other large research programmes using spatial distribution of diversity include the Global 200 programme by the WWF (Olson \& Dinerstein 1998, Olson et al. 2001). Again in this assessment South East Asia is marked out as an area of conservation concern. The Global 200 consists of ecoregions of the earth considered exceptional in their biodiversity containing highly distinctive or irreplaceable taxa (Olson \& Dinerstein 1998, Olson et al. 2001). South East Asia contains 18 of the WWF's 142 terrestrial ecoregions, 11 of which are considered Critically Endangered, 6 Vulnerable and only one as Relatively Stable or intact. The later one is the ecoregion of New Guinea Montane Forest, which matches our assessment of the areas general conservation status. However, the WWF do assign vulnerable status to the Southern New Guinea Lowland Forest, which is predictable as lowland forest is the most threatened of South East Asian habitats (Davis 1995). At generic level and using the Human Footprint data we asses that certain areas of South East Asia are highly threatened, in particular the Philippines and Java. These areas are highly diverse and yet much of their natural habitat has been destroyed by human activity.

\section{CONCLUSIONS}

Preliminary analysis of our database has shown that the entire region of South East Asia including all of Indo-China shares a rich, diverse flora at genus level (Fig. 1, 2). At this scale the eastern boundary of Malesia is clearly east of New Guinea, rather than the Solomon Islands (cf. Johns 1995); these and the Bismarck Archipelago are more similar floristically to the South West Pacific island groups. Some areas high in generic diversity are under significant threat from human pressures: these areas, notably Java and the Philippines, are perhaps not the areas expected for conservation targets due to the low levels of natural habitat left. This result is largely due to the greater influence of the Human Footprint data in our combined analysis, suggesting that in South East Asia, the threat level might be the most important component of any conservation assessment on a regional level, rather than biodiversity richness.

The large islands of South East Asia, Borneo and New Guinea, do not stand out as conservation priorities in this analysis, but if conservation priority were to focus on intactness and low human density then these areas (particularly New Guinea) would be targets under these criteria. With limited resources for conservation the question of whether to protect intact habitats or those severely under threat remains. Our analysis so far has shown that there are correlations with other large-scale conservation categories, showing that generic level data can be usefully used, where perhaps a full species account of a region has not been compiled. As our dataset is mainly based on records from specimens it includes historical records and very recent biodiversity data. We believe that because of the large amount of data collected for this analysis, the patterns shown here at the broad (TDWG) regional scale are still valid in the contemporary South East Asia landscape. For an investigation into these patterns at a more local scale, some data may need to be removed where habitats have been lost and/or genera have been removed from an area. The historical property of our data will allow us to look at conservation issues through time and may be useful in exploring plant distributions under climate change models looking at previous and future distributions. Future work hopes to further explore these distributions and correlations with other conservation categories. Given the deforestation in South East Asia, it is also important to note that many areas have lost all their primary forest and that the 


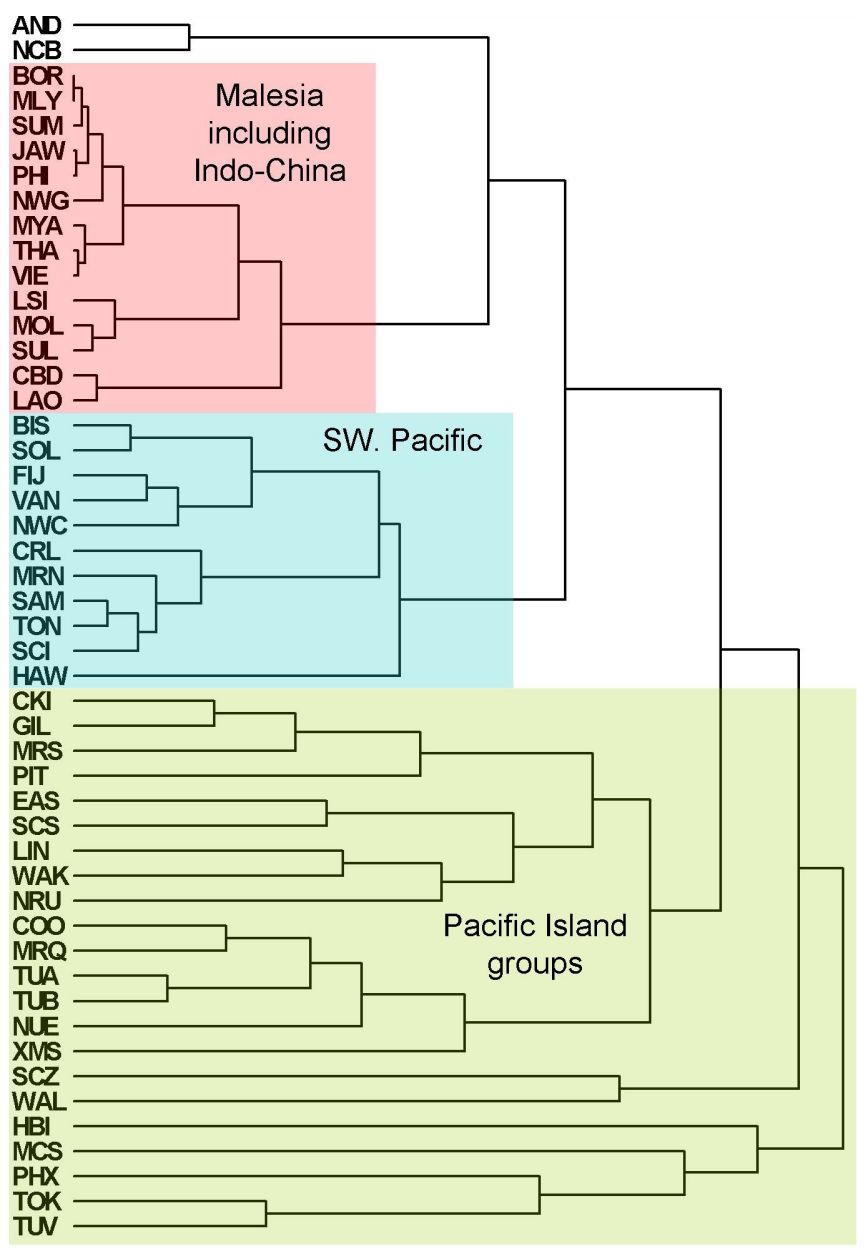

Fig. 5 Dendrogram of floristic relationships within the South East Asia region. Indo-China is again closely aligned with Malesia, and New Guinea (NWG) is closely aligned to Malesia and not to the Bismarck Archipelago (BIS) and the Solomon Islands (SOL). The Pacific islands and island groups are grouped together with the rest of the Pacific forming a distinct group.

majority of conservation effort now lays in identifying the areas with secondary vegetation with high remaining biodiversity. In order to do this it is important that all the available data is used; the fact that some of this biodiversity is now lost is regrettable but not relevant in this part of the analysis. We would like to address this in more detail with country-by-country analysis of biodiversity and human impact.

Global biodiversity distribution maps will always be very good political tools for conservation and for drawing the attention of the general public. It is our belief that these maps can also be used at a regional level to set conservation priorities and compare the needs of different areas in a world where, unfortunately, not everything can be saved.

Acknowledgements Thanks to Justin Moat and Steve Bachman (GIS Unit, RBG Kew) for technical help.

\section{REFERENCES}

Achard F, Eva HD, Stibig H-J, Mayaux P, Gallego J, Richards T, Malingreau J-P. 2002. Determination of deforestation rates of the world's humid tropical forests. Science 297: 999-1002.

Beaman JH. 2005. Mount Kinabalu: Hotspot of plant diversity in Borneo. In: Friis I, Balslev $\mathrm{H}$ (eds), Plant diversity and complexity patterns: local, regional and global dimensions. Biologiske Skrifter 55: 103-127.

Brummitt NA. 2005. Patterns in the global distribution of flowering plant genera. In: Friis I, Balslev H (eds), Plant diversity and complexity patterns: local, regional and global dimensions. Biologiske Skrifter 55: 539-564.

Brummitt NA, Nic Lughadha E. 2003. Biodiversity - where's hot and where's not. Conservation Biology 17: 1442-1448.

Brummitt RK. 2001. World geographical scheme for recording plant distributions, 2nd ed. Hunt Institute, Pittsburgh, USA.

Campbell DG, Hammond HD. 1989. Floristic inventory of tropical countries. NYBG Press.

Conservation International. 2008. Biodiversity hotspots, conservation international (http://www.biodiversityhotspots.org).

Davis SD. 1995. Regional overview: South East Asia (Malesia). In: Heywood VH, Davis SD (eds), Centres of plant diversity 2: 229-299.

Frodin D. 2001. Guide to the standard floras of the world, 2nd ed. CUP.

Johns RJ. 1995. Malesia - An introduction. Curtis's Botanical Magazine 12, 2: $52-62$.

McCune B, Mefford MJ. 1999. PC-ORD: Multivariate analysis of ecological data, version 4.0. Gleneden Beach, Oregon, USA.

Mittermeier RA, Mittermeier CG, Brooks TM, Pilgrim JD, Konstant WR, Da Fonseca GAB, Kormos C. 2003. Wilderness and biodiversity conservation. Proceedings of the National Academy of Sciences. Vol. 100. No. 18: 10309-10313.

Mittermeier RA, Myers N, Mittermeier CG, Gil PR. 1999 Hotspots: Earth's biologically richest and most endangered terrestrial ecoregions. CEMEX Conservation International and Agrupacian Sierra Madre, Mexico.

Mutke J, Barthlott W. 2005. Patterns of vascular plant diversity at continental to global scales. In: Friis I, Balslev H (eds), Plant diversity and complexity patterns: local, regional and global dimensions. Biologiske Skrifter 55: $521-531$.

Myers N, Mittermeier RA, Mittermeier CG, Da Fonseca DAB, Kent J. 2000. Biodiversity hotspots for conservation priorities. Nature 403: 853-858.

Olson DM, Dinerstein E. 1998. The Global 200: A representative approach to conserving the earth's most biologically valuable ecoregions. Conservation Biology 12: 502-515.

Olson DM, Dinerstein E, Wikramanayake ED, Burgess ND, Powell GVN, Underwood EC, D'Amico JA, Itoua I, Strand HE, Morrison JC, Loucks CJ, Allnutt TF, Ricketts TH, Kura Y, Lamoreux JF, Wettengel WW, Hedao P, Kassem KR. 2001. Terrestrial ecoregions of the world: A new world map of life on Earth. BioScience 51: 933-937.

Ridder-Numan JWA. 1996. The historical biogeography of the Southeast Asian genus Spatholobus (Legum.-Papilionoideae) and its allies. Blumea, Suppl. 10.

Sanderson EW, Jaiteh M, Levy MA, Redford KH, Wannebo AV, Woolmer G. 2002. The human footprint and the last of the wild. BioScience 52: $891-$ 904.

Schuster RM. 1972. Continental movements, "Wallace's Line" and Indomalayan - Australasian dispersal of land plants: some eclectic concepts. The Botanical Review 38: 3-86.

Sodhi NS, Pin Koh L, Brook BW, Ng PKL. 2004. Southeast Asian biodiversity: an impending disaster. Trends in Ecology and Evolution 19: 664-660.

Van Steenis CGGJ. 1950. The delimination of Malesia and its main plant geographical divisions. Flora Malesiana, Ser. I, Vol. 1: Ixx-Ixxv.

Van Steenis-Kruseman MJ. 1974. Malesian plant collectors and collections. Supplement II. Flora Malesiana, Ser. I, Vol. 8: i-cxv.

Van Welzen PC, Slik JWF, Alahuhta J. 2005. Plant distribution patterns and plate tectonics in Malesia. In: Friis I, Balslev H (eds), Plant diversity and complexity patterns: local, regional and global dimensions. Biologiske Skrifter 55: 199-217.

Whitmore TC. 1982. Wallace's Line: A result of plate tectonics. Annals of the Missouri Botanical Garden 69: 668-675. 